\title{
Um teatro sem teatro: a teatralidade como campo expandido
}

\section{A theater without theater: the theatricality as expanded field}

\section{Un teatro sin teatro: la teatralidad como campo expandido ${ }^{1}$}

\author{
Ileana Diéguez² \\ (Tradução: Eli Borges)
}

\author{
Resumo \\ O texto busca refletir sobre a teatralidade para além do campo do teatro, retomando teóricos como \\ Alain Badiou, e Michael Fried. \\ Palavras chave: Performance, Teatro, Teatralidade, Vida
}

\begin{abstract}
The text aims to reflect on the theatricality beyond the field of theater theorists like Alain Badiou and Michael Fried.

Keywords: Life, Performance, Theater, Theatricality.
\end{abstract}

O estar presente é uma graça.

M. Fried

Há vários anos tenho me interessado em pensar a teatralidade, entendida como um discurso e uma estratégia que atravessa o teatro e o transcende, possibilitando inclusive a expansão e o deslocamento dos limites do teatral e do artístico. A teatralidade como dispositivo que tem caracterizado uma parte importante da arte contemporânea desde a segunda metade do século XX. Muito antes de o teatro se apropriar de outras linguagens na era do chamado teatro pós-moderno, a teatralidade já havia se disseminado, contaminado, infiltrado e expandido nos territórios da vida e das artes.

A teatralidade é uma disposição complexa e mutante e, como precisou Alain Badiou (2007), não é redutível à cena nem à interpretação de um dado prévio. Quando, nos anos 60, o teatral esteve no centro dos debates artísticos, o reconhecimento de

1 Título original.

2 Professora pesquisadora da Universidade Autônoma Metropolitana (UAM-Cuajimalpa, Mexico). 
uma teatralidade que emergia na cena artística visual deu espaço para que um crítico como Michael Fried (2004, p. 190) declarasse: "O que tem se instalado entre as artes é o teatro", ao mesmo tempo em que tentava advertir: "A arte degenera quando adquire a condição de teatro" (FRIED, 2004, p. 189).

Essa polêmica em torno de uma modalidade discursiva que permeou as artes visuais durante a segunda metade do século XX orientou boa parte da crítica e da teoria artística contemporânea, alimentando não poucos prejuízos em torno do teatral e impulsionando a polarização entre as práticas performativas e as teatrais.

O texto em que Michael Fried expressou as citadas declarações foi publicado na [revista] Artforum 5, em junho de 1967, com o título "Art and Objecthood", integrando várias publicações posteriores, entre elas Minimal Art: A critical Anthology, organizada por Gregory Battcock (1968) e publicada depois pelo próprio Fried junto a outros textos, sob o título Art and Objecthood: Essays and Reviews, em 1998³.

No ensaio, Michael Fried alertava sobre uma transformação radical que vinha se produzindo no campo da escultura e que ameaçava instalar-se entre as artes. Tal transformação foi analisada uma década depois por Rosalind Krauss em seu histórico ensaio "A escultura no campo expandido"4 e tornou-se evidente no comentário de Donald Judd: "A metade ou mais das melhores obras dos últimos anos não têm sido nem pinturas nem esculturas" (MARZONA, 2004, p. 11). Ao questionar o fundamento das concepções tradicionais da escultura e da pintura, a chamada Minimal Art - na qual se incluía a obra de Judd - começou a introduzir a problemática dos campos expandidos.

Esse foi um período no qual alguns artistas deixaram de produzir quadros ou pinturas a serem colocados sobre paredes planas para então instalar objetos nas salas de arte e em espaços abertos. Os objetos, com sua imponente presença, tomaram os espaços e produziram uma presença cênica que demandava atenção ou expectativa. Ante tal tipo de obras, Fried observou a emergência de uma teatralidade instalada nas artes visuais e que operava por meio da exibição de objetos expostos em uma dimensão temporal à percepção e à experiência do espectador. Em diálogo com a perspectiva de Clement Greenberg, Fried não via com bons olhos a instalação de objectualidades ${ }^{5}$ por

\footnotetext{
3 Consultamos a versão em espanhol Arte y objetualidad: ensayos y reseñas. Madrid: A. Machado Libros, 2004. 4 Publicado pela primeira vez na [revista] October 8 (Primavera, 1979).

5 N. do T.: De tradução controversa, optamos por corresponder o termo "objetualidades", em espanhol, ao verbete "objectualidade", que no português parece se aproximar mais ao significado pretendido na versão original, ou seja, a ideia de materialidade ou a condição de objeto.
} 
parte dos chamados artistas minimalistas ${ }^{6}$, pois se tratava de objetos "em situação" que implicavam uma experiência (FRIED, 2004, p. 179). Ambos os críticos consideraram que tal arte, a que chamaram de "literalista", gerava uma "presença em cena"” por meio da imponente aparência dos objetos que exigiam ser levados em conta e solicitavam uma relação de cumplicidade com os espectadores ${ }^{8}$. Esse era o efeito ou qualidade teatral contra a qual se expressou tal crítica, inaugurando uma espécie de manifesto que falsamente enfrentava o teatral e o pictórico $0^{9}$ e que abertamente se opunha à expansão de uma sensibilidade "corrompida ou pervertida pelo teatro" (FRIED, 2004, p. 186). Não era a distinção entre os regimes modernos e pós-modernos o que estava se evidenciando nesse temor ao teatral?

Em explícita confrontação com a ideia de que "a sobrevivência das artes tem dependido, cada vez mais, de sua habilidade em vencer o teatro" (FRIED, 2004, p. 188), e justamente para demonstrar o contrário, concebe-se a exposição Um teatro sem teatro, organizada pelo Museu d'Art Contemporani de Barcelona em coprodução com o Museu Colec区ão Berardo - Arte Moderna e Contemporânea, de Lisboa, e exibida em ambos os museus entre maio de 2007 e fevereiro de 2008. Em catálogo homônimo $^{10}$, incluem-se importantes documentos e registros fotográficos que dão conta da "outra cena" que foi se impondo no campo das artes visuais; ou como expressou Manuel Borja-Villel (2007, p. 20), diretor geral do projeto, buscou-se examinar o modo em que "o teatral tem transformado nossa percepção da natureza da obra de arte e sua situação na divisão do visível".

6 A Minimal Art, assim chamada pelo crítico e filósofo Richard Wollheim em 1965, em sentido estrito somente acolheu os objetos, esculturas e instalações de cinco artistas de uma mesma geração, todos residentes em Nova York durante a década de 60: Donald Judd, Robert Morris, Carl Andre, Dan Flavin e Sol LeWitt.

7 Segundo Fried (2004, p. 180): "Diz-se que algo tem presença quando esse exige ser levado em conta pelo espectador".

8 Tal situação foi muito acentuada nas obras de Robert Morris, particularmente em suas caixas antropomórficas e nos cubos de Tony Smith, o qual por sua vez declarava que não os concebia como esculturas senão "como presenças" (cit. em FRIED, 2004, p. 182).

9 Cito as radicais palavras de Fried: “... o imperativo de que a pintura modernista anule ou suspenda sua objectualidade é, no fundo, o imperativo de que aquela anule ou suspenda o teatro. E isso significa que há uma guerra constante entre o teatro e a pintura modernista, entre o teatral e o pictórico" (2004, p. 185). Ou inclusive que: "o teatro e a teatralidade não estão hoje em guerra, simplesmente, com a pintura modernista (ou com a pintura e a escultura modernistas), senão com a arte como tal - e na medida em que as diferentes artes possam ser descritas como modernistas, com a sensibilidade modernista como tal" (2004, p. 188).

10 Un teatro sin teatro. Barcelona/Lisboa: Museu d'Art Contemporani de Barcelona e Museu Colec囚ão Berardo - Arte Moderna e Contemporânea de Lisboa, 2007. 
A concepção geral do catálogo está entremeada pela problematização da desacertada visão de Michael Fried, o que se expressa na opinião de Patricia Falguières (2007, p. 28), segundo a qual o texto do referido autor representa "um dos ensaios críticos em menos conformidade com sua época produzidos pelo século XX"11. Tal ensaio fora contraditoriamente escrito nos anos da eclosão e do impetuoso desenvolvimento do happening, da performance, dos eventos de John Cage e Merce Cunningham, do movimento Fluxus, do Acionismo Vienense, dos assemblages, dos environments, da pop art, da land art, dentre muitos outros, quando a temporalidade e o princípio de a tudo encenar tomaram as artes visuais, e emergiu essa outra cena que poderia ser denominada como a teatralidade da plástica. A teatralidade gerada pelas disposições de objetos e encenações escultóricas desenvolveu-se de maneira paralela às teatralidades do corpo exploradas por performers e criadores do espaço teatral, como Artaud e Grotowski. Desvinculado de origens dramáticas e textuais, esse "outro teatro" implicava reconhecer outras genealogias, não de raízes dramáticas, mas cênicas e plásticas, tal como experimentado e teorizado por Tadeusz Kantor.

Em um dos primeiros textos do catálogo (2007, p. 20), Alan Badiou, em entrevista a Elie During, afirma estar convencido de que derrotar a teatralidade é uma tarefa tão difícil quanto anular a representação: "talvez não seja tão fácil «sair» do teatro ou anulá-lo interiormente. De fato, o teatro não é redutível à cena e a sua perspectiva, nem sequer à interpretação de um dado prévio (um texto ou um protocolo para as improvisações...). O teatro é uma disposição complexa, cuja sequência material não resulta imutável."

Além do teatro habitual, a arte é o cenário de "outro teatro." Cria-se espaço cênico em uma instalação plástica: um espaço de encenação e expectativa como nas instalações de Christian Boltansky; ou nas cenas e narrativas visuais, prévias à instantânea fotográfica, criadas por Joel-Peter Witkin. Durante o século XX, as artes experimentaram cada vez mais as hibridações e impurezas, de maneira que aquilo inicialmente sugerido como "outro teatro" é, na realidade, o reconhecimento da teatralidade como um campo expandido.

Como já se tem legitimado ou polemizado, a teatralidade tornou-se uma das características mais relevantes da arte contemporânea. Contra toda possibilidade de pureza, de uma essencialidade que depura e separa radicalmente as diversas formas artísticas, a arte reconhece-se hoje como "uma estrutura de acontecimento", de situações, de práticas in situ, de teatralidades, de performatividades e (re)presentações.

11 "Playground", em Un teatro sin teatro (2007, p. 28-34). 
A prática da ação in situ (site specific) implicou o desenvolvimento cênico de uma arte que já não queria ser vista na caixa branca das galerias e museus, nem em seu contrário, nas caixas pretas do teatro. As transformações e expansões do performativo, do teatral e do cênico não têm ocorrido somente por conta das contaminações e disseminações indisciplinares das artes, senão insistentemente pelas demandas e contaminações que os acontecimentos da vida propõem à arte, pela urgência com que nos interpelam as cenas e teatralidades das polis. Dessa forma, a teatralidade como campo expandido não só nos exige reconhecer as outras cenas e o outro teatro que emerge nos interstícios artísticos, mas também nos intima a reconhecer a teatralidade que habita na vida e nas representações sociais, tal como o fizeram Artaud e Evreinov. A teatralidade como campo expandido para além das artes.

Curiosamente, as últimas palavras de Fried, ao finalizar Art and Objecthood, evidenciam seu temor e, ao mesmo tempo, seu reconhecimento à "enorme penetração" - prefiro dizer, expansão - da teatralidade "em relação a nossas vidas", ao modo em que nos envolve e em que compromete a presença: "O estar presente é uma graça" (FRIED, 2004, p. 194).

\section{Referências}

ARTAUD, Antonin. El teatro y su doble. La Habana: Instituto Cubano del Libro, 1969.

BADIOU, Alain y DURING, Elie. Un teatro de la operación. En: Un teatro sin teatro. Museu d'Art Contemporani de Barcelona y Museu Colec囚ão Berardo-Arte Moderna e Contemporânea de Lisboa, 2007, pp. 22-27.

BORJA-VILLEL, Manuel. Un teatro sin teatro: el lugar del sujeto. En: Un teatro sin teatro. Museu d'Art Contemporani de Barcelona y Museu Colec区ão Berardo-Arte Moderna e Contemporânea de Lisboa, 2007, pp.20-21.

EVREINOV, Nicolás. El teatro en la vida. Santiago de Chile: Ercilla, 1936.

FALGUIĖRES, Patricia. Playground. En: Un teatro sin teatro. Museu d'Art Contemporani de Barcelona y Museu Colec囚ão Berardo-Arte Moderna e Contemporânea de Lisboa, 2007, pp. 28-34.

FRIED, Michael. Arte y objetualidad. Ensayos y reseñas. Madrid: A. Machado Libros, 2004. KANTOR, Tadeusz. El teatro de la muerte (selec. y presentación Denis Bablet). Buenos Aires: La Flor, 1984.

KRAUSS, Rosalind. La escultura en el campo expandido. En: La posmodernidad (Sel. y pról. Hal Foster). México: Kairós, 1988, pp. 59-74.

MARZONA, Daniel. Arte minimalista. Köln: Taschen, 2004. 